\title{
The Effect of Changes in Cervical Cancer Screening Guidelines on Chlamydia Testing
}

\author{
Michelle S. Naimer, MD, MHSc ${ }^{1,2, *}$ \\ Jeffrey C. Kwong, MD, MSc 1,3,4,6,7,* \\ Deepit Bhatia, $\mathrm{MPH}^{3}$ \\ Rabim Moineddin, $\mathrm{PbD}^{1,3,7}$ \\ Michael Whelan, MSc ${ }^{4}$ \\ Michael A. Campitelli, MPH ${ }^{3}$ \\ Liane Macdonald, MD, MSc ${ }^{4,7}$ \\ Aisha Lofters, MD, $\mathrm{PbD}^{1,3,5,7}$ \\ Asbleigh Tuite, MSc, MPH \\ Tali Bogler, $M D^{1,8}$ \\ Joanne A. Permaul, $M A^{2}$ \\ Warren J. McIsaac, MD, MSc ${ }^{1,2}$ \\ *These authors contributed equally as first authors. \\ 'Department of Family and Community \\ Medicine, University of Toronto, Toronto, \\ Canada \\ ${ }^{2}$ Mount Sinai Hospital, Sinai Health \\ System, Toronto, Canada \\ ${ }^{3}$ Institute for Clinical Evaluative Sciences, \\ Toronto, Canada \\ ${ }^{4}$ Public Health Ontario, Toronto, Canada \\ ${ }^{5}$ Centre for Urban Health Solutions, Li Ka \\ Shing Knowledge Institute, St. Michael's \\ Hospital, Toronto, Canada \\ ${ }^{6}$ University Health Network, Toronto, \\ Canada \\ ${ }^{7}$ Dalla Lana School of Public Health, \\ University of Toronto, Toronto, Canada \\ ${ }^{8}$ St. Michael's Hospital, Toronto, Canada

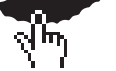 \\ MORE ONLINE \\ www.annfammed.org
}

Conflicts of interest: authors report none.

\section{CORRESPONDING AUTHORS}

Michelle S. Naimer, MD, MHSc Mount Sinai Academic Family Health Team 60 Murray Street, 4th Floor Toronto, Ontario M5T 3L9 CANADA michelle.naimer@sinaihealthsystem.ca Jeffrey C. Kwong, MD, MSc Institute for Clinical Evaluative Sciences 2075 Bayview Ave, Room G1-06 Toronto, Ontario M4N 3M5 CANADA jeff.kwong@utoronto.ca

\begin{abstract}
PURPOSE Many chlamydia infections are identified through screening, which is frequently offered to females concomitantly with cervical cancer screening. Recent cervical cancer screening guidelines recommend screening less frequently and starting later. We sought to evaluate the impact of the May 2012 Ontario, Canada, cervical cancer screening guideline change on Papanicolaou (Pap) and chlamydia trachomatis (chlamydia) testing and incidence.
\end{abstract}

METHODS We extracted population-based physician billing claims data to identify Pap and chlamydia tests and public health surveillance data to identify chlamydia cases. We used interrupted time series analysis of quarterly data spanning 2 years before and after the guideline change and fitted segmented linear regression or rational functions to the outcomes using autoregressive integrated moving average models. Outcomes were stratified by sex and age group.

RESULTS Two years after the guideline change, we observed reduced chlamydia testing in females, with the greatest relative reduction (25.5\%) among those aged 15 to 19 years. We also observed decreases in reported chlamydia incidence for females aged 15 to 19 years and 20 to 24 years (relative reductions of $16.8 \%$ and $14.4 \%$, respectively). Chlamydia incidence remained the same for males, despite increased chlamydia testing.

CONCLUSIONS Recent cervical cancer screening guideline changes in Ontario were associated with reduced chlamydia testing and reported new cases of chlamydia in females. Females aged 15 to 19 years, who are at high risk for chlamydia if sexually active, and who no longer warrant cervical cancer screening, were disproportionately affected. Females should be tested for chlamydia based on risk, regardless of need for Pap testing.

Ann Fam Med 2017;15:329-334. https://doi.org/10.1370/afm.2097.

\section{INTRODUCTION}

C blamydia trachomatis (chlamydia) is the most commonly diagnosed bacterial sexually transmitted infection (STI) worldwide. ${ }^{1,2}$ The burden of chlamydia infection is greatest among sexually active adolescents and young adults aged 15 to 29 years. Infection can result in significant morbidity, including pelvic inflammatory disease, ectopic pregnancy, neonatal illness, and infertility. ${ }^{1,3}$

Because most chlamydia infections are asymptomatic and because females are disproportionately affected by complications, chlamydia prevention programs screen young females and test male partners of females infected with chlamydia. ${ }^{4}$ One commonly used strategy has been to screen females for chlamydia concomitantly with cervical cancer screening (ie, when doing Papanicolaou [Pap] tests). ${ }^{5}$

New cervical cancer screening guidelines recommend beginning screening later and screening less frequently. In March, 2012, the US Preventive Services Task Force (USPSTF) and the American Cancer Society recommended screening women aged 21 to 65 years every 3 years and eliminating screening for women younger than 21 years. ${ }^{6}$ Cancer Care Ontario (a governmental agency responsible for cancer services in 
Ontario, Canada) and the Canadian Task Force on Preventive Health Care updated their cervical cancer screening guidelines to follow suit in May 2012 and January 2013, respectively. ${ }^{7,8}$

The objective of this study was to assess the population-level impacts of increased cervical cancer screening intervals and delayed initiation of screening on chlamydia testing and reported chlamydia incidence in young adult females.

\section{METHODS}

\section{Study Setting and Population}

Free health insurance is provided to virtually all Ontario residents through the Ontario Health Insurance Plan (OHIP). Both Pap and chlamydia tests are offered free of charge through physician offices, hospitals, public health department or community-based sexual health clinics, post-secondary student health services, and community health centers. ${ }^{9}$

The study population included all females and males in Ontario aged 15 to 29 years between May 2010 and July 2014, covering approximately 2 years before and after release of the new cervical cancer screening guidelines in May 2012. ${ }^{7}$ Males were included in the study as a comparison group, since the guideline changes were expected to have no impact on them.

Ethical approval for this study was obtained from the Research Ethics Boards of Mount Sinai Hospital and Sunnybrook Health Sciences Centre, both in Toronto, Canada.

\section{Data Sources and Definitions}

We obtained data on Pap tests from the OHIP database, which captures billing claims submitted by about $94 \%$ of Ontario physicians. ${ }^{10}$ Pap tests were identified using OHIP service codes billed by physicians collecting Pap smears and/or OHIP laboratory codes billed by commercial laboratory physicians interpreting cervicovaginal specimens (Supplemental Appendix, available at http:// www.annfammed.org/content/15/4/329/suppl/DC1). ${ }^{11}$

Chlamydia tests were identified from 2 sources: (1) the OHIP database, which captures chlamydia tests performed at commercial laboratories; and (2) Public Health Ontario's laboratory information management system (LabWare), which captures chlamydia tests performed in STI clinics, including specimens submitted without a valid OHIP number. ${ }^{12}$ In this study, $1,357,840$ (64.8\%) chlamydia tests were identified from the OHIP database and 738,743 (35.2\%) were identified from the LabWare database.

We identified chlamydia cases from the Integrated Public Health Information System (iPHIS), Ontario's reportable disease database. Laboratories and clinicians are legally required to report laboratory-confirmed or probable chlamydia cases to local public health departments, who record case information in iPHIS. ${ }^{13}$

We calculated sex- and age-group-specific outcome rates using Census population estimates for the denominator (details in the Supplemental Appendix). ${ }^{14}$

\section{Statistical Analysis}

Starting from May 2010, we obtained quarterly sexand age-specific aggregate counts of outcomes. The quarters were defined as May to July, August to October, November to January, and February to April. We used interrupted time series analysis to determine the impact of the guideline change on the outcomes, stratified by sex and age group (15 to 19 years, 20 to 24 years, and 25 to 29 years). This method estimates the trend of the outcomes before the release of the new guidelines (intervention), and changes in the outcomes both immediately following the intervention and 2 years later.

We fitted segmented linear regression or rational functions to the outcomes using an autoregressive integrated moving average model to account for autocorrelation, secular trends, and seasonality (Supplemental Appendix). First we used segmented regression to model the association between time and the outcome on a linear scale both before and after the guideline change in May 2012. Second, we used a rational function model, featuring a linear function before the guideline change and a rational function after the guideline change. The latter was used to model the diminishing effects of the guideline change on the outcome with time.

We used parameter estimates of the models to construct fitted models from May 2010 to July 2014. These fitted models were used to calculate absolute and relative changes in the rates at 1 year (May to July 2013) and at 2 years (May to July 2014) after the intervention. We calculated $95 \%$ confidence intervals using the delta method (see the Supplemental Appendix). All tests were 2 -tailed, and we used $P<.05$ as the level of statistical significance.

\section{RESULTS}

Before the guideline change, annual Pap testing rates were higher for older females (Table 1). Chlamydia testing rates were 4.6- to 6.5-fold higher for females than males. Reported incidence of chlamydia was also higher for females than males, with the highest incidence in those aged 20 to 24 years for both sexes.

Pap testing declined in all age groups following the guideline release, with the greatest relative reductions observed for females aged 15 to 19 years (Figure 
Table 1. Study Population and Rates per 1,000 People of Pap Testing, Chlamydia Testing, and Reported Chlamydia Incidence in 2011, by Sex and Age-group

\begin{tabular}{lcccc}
\hline & Population & $\begin{array}{c}\text { Pap } \\
\text { Testing }\end{array}$ & $\begin{array}{c}\text { Chlamydia } \\
\text { Testing }\end{array}$ & $\begin{array}{c}\text { Chlamydia } \\
\text { Incidence }\end{array}$ \\
\hline Females & & & & \\
15-19 years & 426,446 & 355.9 & 207.1 & 15.2 \\
20-24 years & 461,607 & 898.3 & 393.9 & 19.3 \\
25-29 years & 465,399 & $1,051.6$ & 351.3 & 8.4 \\
Males & & & & \\
15-19 years & 446,118 & $n / a$ & 31.7 & 3.8 \\
20-24 years & 483,861 & $n / a$ & 83.6 & 9.9 \\
25-29 years & 467,943 & $n / a$ & 75.9 & 6.2 \\
\hline Pap = Papanicolaou. & & & \\
\hline
\end{tabular}

same age-groups observed in this study. ${ }^{15}$ The declines were likely smaller in this study because diagnostic tests (not distinguishable from screening tests in this study) should be unaffected by the guideline change. Similarly, a second study of 5 family medicine clinics at the University of Michigan evaluated the impact of the 2009 American College of Obstetricians and Gynecologists recommendation to begin cervical cancer screening at age 21 years on chlamydia screening for females aged 15 to 21 years. The study concluded that women in that age group had higher odds of being screened for chlamydia before the guideline change (odds ratio $=13.97 ; 95 \% \mathrm{CI}, 9.17-21.29) .{ }^{16}$

In our study, decreased identification of 1A, Table 2). Since older females had higher baseline rates, the absolute decreases were larger for older age-groups.

After the new guideline, chlamydia testing also decreased for all females, with the greatest relative reductions in the youngest age-group (Figure 1B, Table 2). In contrast, we observed small increases in chlamydia testing in males aged 20 to 24 years and 25 to 29 years 2 years after the guideline change (Figure 1C, Table 2).

We observed decreases in reported chlamydia incidence for females aged 15 to 19 years and 20 to 24 years, but not 25 to 29 years (Figure 1D, Table 2). Rates were unchanged for males (Figure 1E, Table 2).

Parameter estimates for the rational function and segmented regression models are presented in the Supplemental Appendix.

\section{DISCUSSION}

The 2012 change in the Ontario cervical cancer screening guideline was associated with reduced Pap and chlamydia testing in females aged 15 to 29 years and reduced identification of chlamydia cases in females aged 15 to 19 years and 20 to 24 years. The 15 to 19 age group, in whom Pap smears are no longer recommended, was disproportionately affected. The reported incidence of chlamydia remained the same for males despite increased testing.

Our findings are consistent with 2 recent studies that also evaluated the impact of changes to cervical cancer screening guidelines. The first, a review of 200 patient charts from 5 family medicine clinics in Toronto, Ontario, found a 50\% decrease in chlamydia screening among females aged 15 to 24 years following the 2012 Ontario guideline change, compared to the $18 \%$ to $26 \%$ decline in chlamydia testing for the chlamydia in females aged 15 to 19 years and 20 to 24 years was paralleled by decreased testing, suggesting that reduced testing for chlamydia in females leads to reduced detection of asymptomatic chlamydia infections. Using the observed rates of reported chlamydia cases for Ontario in 2014 and the absolute rate reductions of reported chlamydia infections observed for females aged 15 to 29 years 2 years after the guideline change, and assuming that the true incidence of chlamydia (symptomatic and asymptomatic combined) in the population was unchanged over this period, we estimated that 2,726 fewer cases of chlamydia were detected per year in Ontario following the guideline change. If decreased testing reflected decreased screening, this likely represented reduced detection of asymptomatic infections. The public health implications of reduced chlamydia screening over time include missed opportunities for clinical and public health management of cases and potentially increased spread of chlamydia infection by asymptomatic individuals. Notably, following a decrease in chlamydia incidence in Ontario in 2012 and 2013, chlamydia incidence began to increase in 2014. ${ }^{17}$ As of December 2015, reported chlamydia incidence has continued to increase compared to historical averages. ${ }^{17}$ Although the reasons for these overall population trends over time are likely multifactorial, the cervical cancer screening guideline change may be one contributing factor.

In contrast to the reduction in chlamydia testing observed in females, chlamydia testing in males increased between 2010 and 2014, likely due to increased availability of non-invasive nucleic acid amplification testing (NAAT) of urine specimens. ${ }^{18}$ Despite more chlamydia testing in males, incidence remained constant. This finding is consistent with the literature affirming insufficient evidence for screening men with average risk. ${ }^{4,19}$ 
Figure 1. Observed and fitted rates of quarterly Pap testing, chlamydia testing, and reported chlamydia rates.
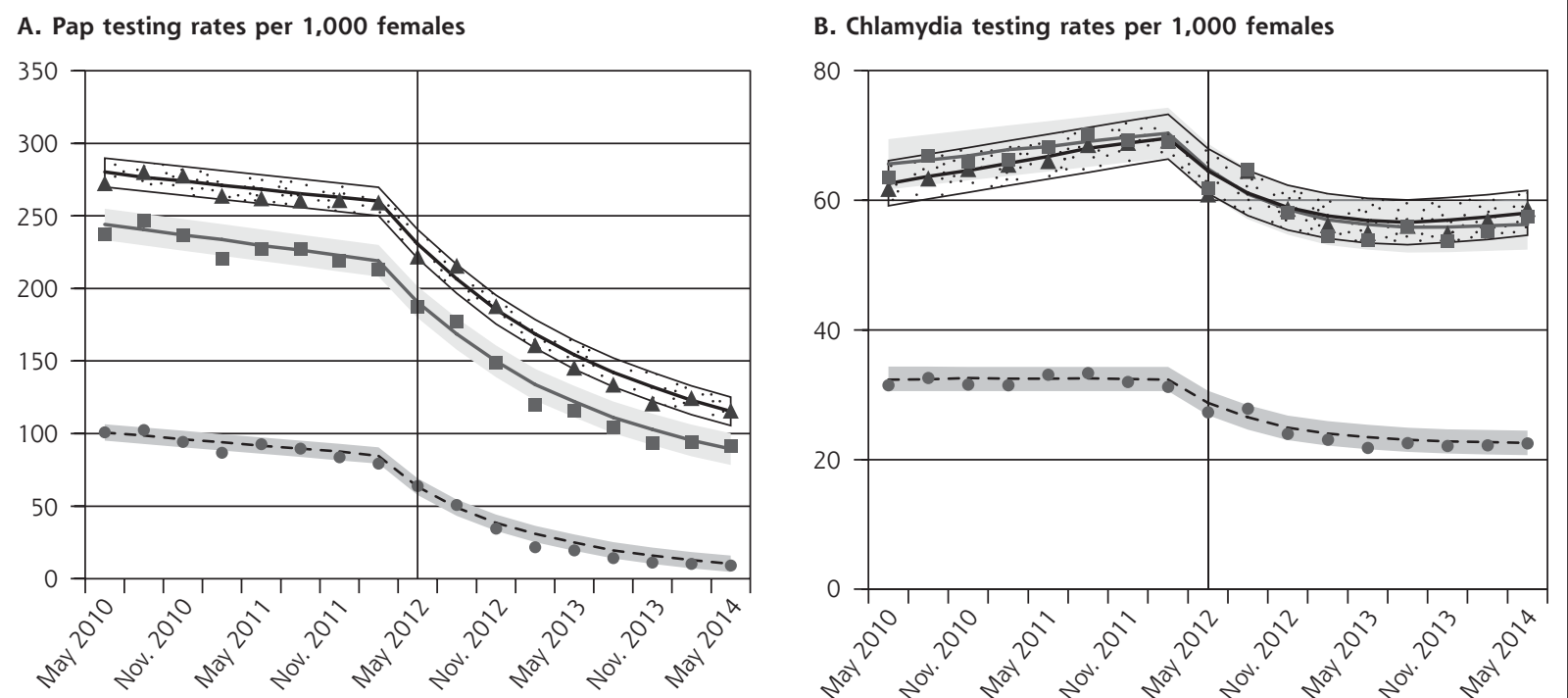

\section{Chlamydia testing rates per 1,000 males}
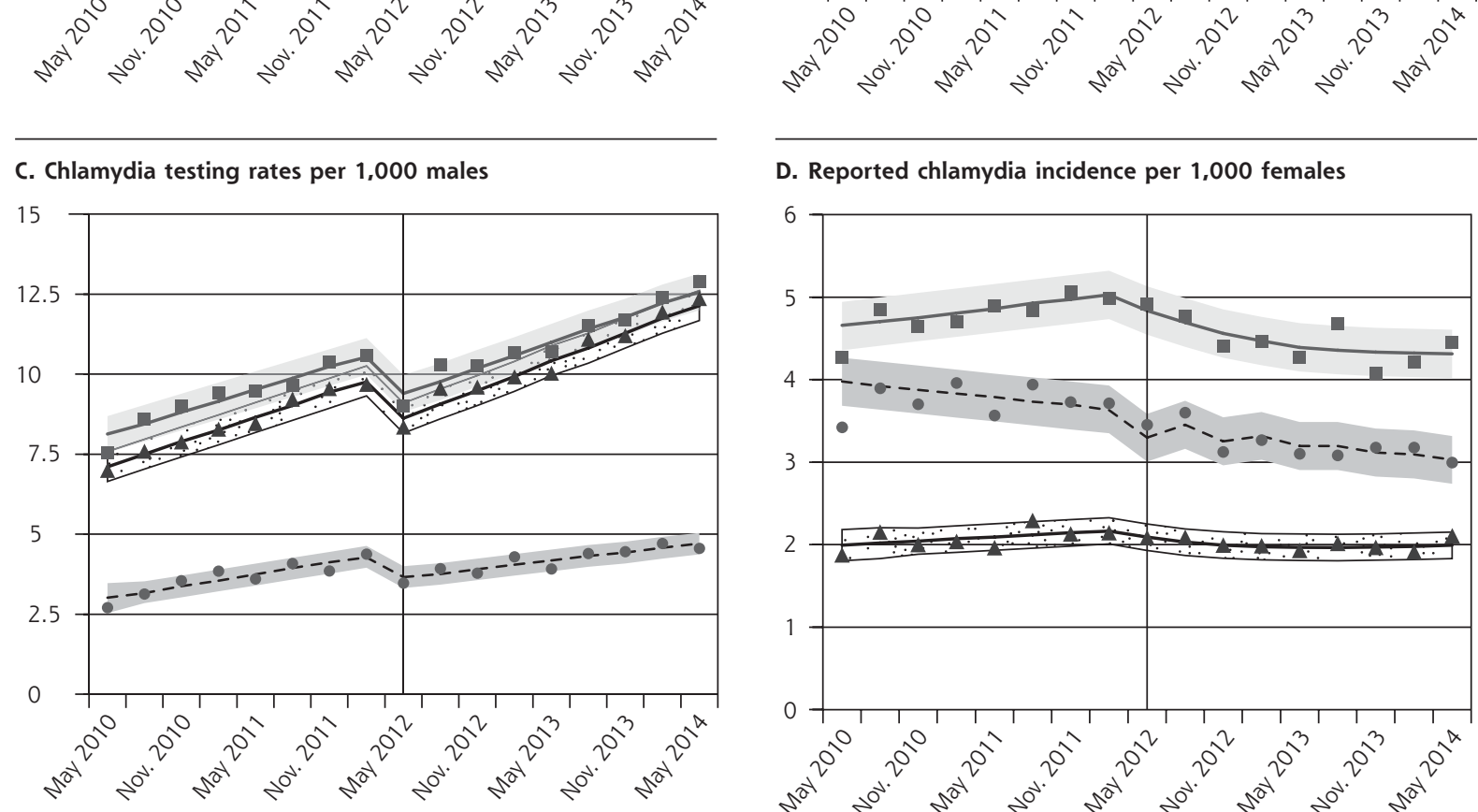

\section{Reported chlamydia incidence per 1,000 females}

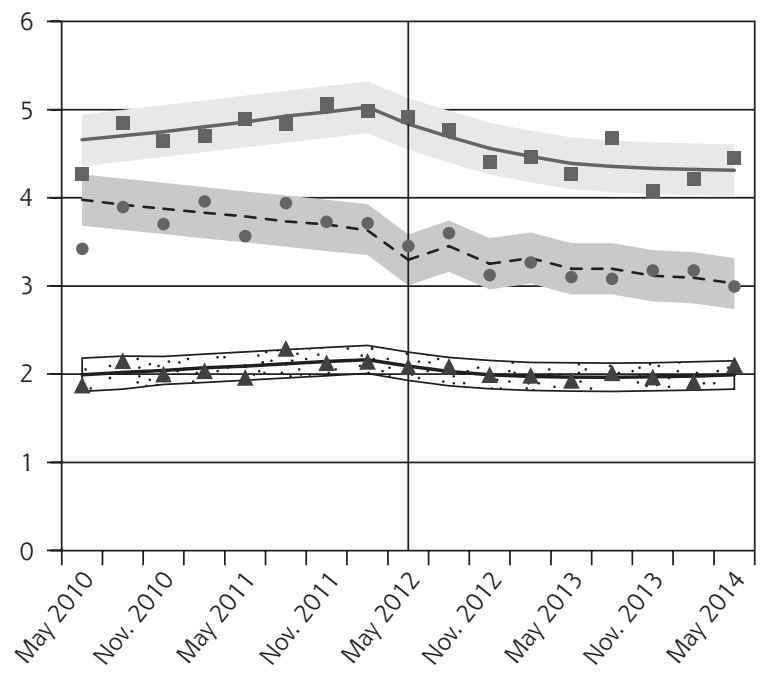

\section{E. Reported chlamydia incidence per 1,000 males}

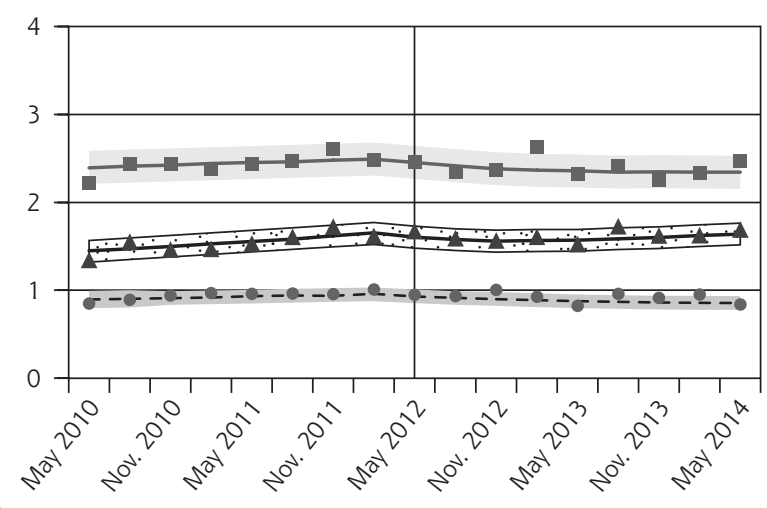

Pap = Papanicolaou

Lines represent the fitted models for the three age groups, and shaded areas represent $95 \%$ confidence intervals.
- 15-19 observed
- - 15-19 fitted model
20-24 observed
-20-24 fitted model
A 25-29 observed
- 25-29 fitted model 
Table 2. Absolute and Relative Changes in Quarterly Rates (per 1,000 people) of Pap Testing, Chlamydia Testing, and Reported Chlamydia Incidence, Comparing Outcomes in the Latest Quarter Before Guideline Change (Feb-Apr 2012) to the Quarters 1 Year and 2 Years After the Guideline Change (May-Jul 2013 and 2014, Respectively)

\begin{tabular}{|c|c|c|c|c|}
\hline Age groups, y & $\begin{array}{c}\text { Absolute Change } \\
\text { per 1,000 People } \\
\text { After } 1 \text { Year }(95 \% \mathrm{Cl})\end{array}$ & $\begin{array}{l}\text { Relative Change } \\
\text { After } 1 \text { Year, \% } \\
(95 \% \mathrm{Cl})\end{array}$ & $\begin{array}{c}\text { Absolute Change } \\
\text { per 1,000 People } \\
\text { After } 2 \text { Years }(95 \% \mathrm{Cl})\end{array}$ & $\begin{array}{l}\text { Relative Change } \\
\text { After } 2 \text { Years, \% } \\
\qquad(95 \% \mathrm{Cl})\end{array}$ \\
\hline \multicolumn{5}{|c|}{ Pap testing, females } \\
\hline $15-19$ & $-61.5(-71.2$ to -51.8$)$ & $-74.2(-83.2$ to -65.2$)$ & $-77.5(-90.2$ to -64.8$)$ & $-93.5(-102.8$ to -84.1$)$ \\
\hline $20-24$ & $-98.2(-116.9$ to -79.4$)$ & $-45.3(-52.4$ to -38.3$)$ & $-131.2(-156.2$ to -107.8$)$ & $-61.0(-69.1$ to -52.9$)$ \\
\hline \multicolumn{5}{|c|}{ Chlamydia testing, females } \\
\hline $15-19$ & $-11.4(-14.9$ to -8.0$)$ & $-22.2(-28.3$ to -16.1$)$ & $-13.1(-17.3$ to -8.9$)$ & $-25.5(-32.7$ to -18.2$)$ \\
\hline $20-24$ & $-16.6(-22.9$ to -10.3$)$ & $-16.5(-22.3$ to -10.7$)$ & $-17.8(-25.5$ to -10.1$)$ & $-17.7(-24.7$ to -10.7$)$ \\
\hline $25-29$ & $-14.4(-20.6$ to -8.3$)$ & $-15.9(-22.1$ to -9.6$)$ & $-14.3(-21.3$ to -7.3$)$ & $-15.7(-22.8$ to -8.6$)$ \\
\hline \multicolumn{5}{|c|}{ Chlamydia testing, males } \\
\hline $15-19$ & $-0.3(-1.1$ to 0.5$)$ & $-3.4(-12.7$ to 5.9$)$ & $0.1(-0.7$ to 0.8$)$ & $1.1(-7.7$ to 10.0$)$ \\
\hline $25-29$ & $0.6(-0.5$ to 1.8$)$ & $3.0(-2.5$ to 8.5$)$ & $2.2(0.9$ to 3.4$)$ & $10.5(4.1$ to 16.9$)$ \\
\hline \multicolumn{5}{|c|}{ Reported chlamydia incidence, females } \\
\hline $15-19$ & $-0.5(-0.9$ to -0.0$)$ & $-12.2(-23.0$ to -1.5$)$ & $-0.6(-1.1$ to -0.1$)$ & $-16.8(-29.5$ to -4.1$)$ \\
\hline $20-24$ & $-0.6(-1.1$ to -0.2$)$ & $-12.6(-20.8$ to -4.5$)$ & $-0.7(-1.2$ to 0.2$)$ & $-14.4(-23.4$ to -5.4$)$ \\
\hline $25-29$ & $-0.2(-0.5$ to 0.1$)$ & $-9.3(-23.6$ to 5.1$)$ & $-0.2(-0.5$ to 0.1$)$ & $-8.0(-21.2$ to 5.3$)$ \\
\hline \multicolumn{5}{|c|}{ Reported chlamydia incidence, males } \\
\hline $15-19$ & $-0.1(-0.2$ to 0.1$)$ & $-7.2(-19.0$ to 4.6$)$ & $-0.1(-0.2$ to 0.0$)$ & $-8.4(-21.0$ to 4.1$)$ \\
\hline $20-24$ & $-0.1(-0.4$ to 0.1$)$ & $-5.1(-14.3$ to 4.0$)$ & $-0.1(-0.4$ to 0.1$)$ & $-5.1(-15.7$ to 5.6$)$ \\
\hline $25-29$ & $-0.1(-0.3$ to 0.1$)$ & $-4.0(-15.1$ to 7.1$)$ & $0.0(-0.2$ to 0.2$)$ & $0.9(-9.9$ to 11.6$)$ \\
\hline
\end{tabular}

Limitations of our study include the previously mentioned inability to distinguish between diagnostic and screening Pap and chlamydia tests. We also included females who might have required specialized cervical cancer screening, such as immunocompromised individuals and those who had had previous abnormal Pap tests and had not yet returned to routine screening. Since women who require specialized screening for cervical cancer or STIs would not be affected by the new cervical screening guidelines, including them in this study likely led to an underestimate of the effects of the guideline change. Also, this study did not include Pap or chlamydia tests performed at certain hospitals, but most Ontario family physicians and gynecologists practice outside of hospitals, and the proportion missed was constant over the study period..$^{20}$ This study examines only 1 province in Canada, so may not be generalizable to other Canadian provinces or to other settings without universal health insurance. This study also lacks a true control group. Finally, similar changes to other cervical cancer screening guidelines (eg, the updated 2013 Canadian Task Force on Preventive Care Guidelines) may have also influenced chlamydia testing in Ontario. ${ }^{8}$

Strengths include the use of population-based data on several outcomes and the use of rigorous inter- rupted time series methods to evaluate the impact of a guideline change as an intervention.

This study highlights the need to separate STI screening recommendations for females from cervical cancer screening recommendations. The American College of Physicians' recommendation against screening pelvic examinations in asymptomatic and nonpregnant women could also potentially impact chlamydia screening rates in females if other screening practices are not adopted..$^{21}$ The USPSTF recently released new chlamydia screening recommendations. ${ }^{19}$ Screening for chlamydia with a NAAT is recommended for all sexually active women aged 24 years or younger, and older women at risk. Canadian guidelines recommend screening at-risk groups (sexually active women and men aged 25 years or younger, older women at risk, and pregnant women) with NAATs for urine, urethral, or cervical specimens. ${ }^{22}$ Effective strategies to increase chlamydia screening in primary care include providing urine collection containers to patients at registration, physicians alerts, staff education, and self-collected vaginal swabs. ${ }^{23,24}$

To read or post commentaries in response to this article, see it online at http://www.AnnFamMed.org/content/15/4/329. 
Submitted August 24, 2016; submitted, revised, February 2, 2017; accepted February 26, 2017.

Key words: chlamydia; cervical cancer; screening; clinical practice guidelines

Prior presentations: North American Primary Care Research Group (NAPCRG) Conference, October 24 - 28, 2015, Cancun, Mexico.

Funding support: This work was supported by the Ray D. Wolfe Department of Family Medicine at Mount Sinai Hospital and the Department of Family and Community Medicine, University of Toronto. This study was also supported by the Institute for Clinical Evaluative Sciences (ICES) and Public Health Ontario (PHO), which are funded by annual grants from the Ontario Ministry of Health and Long-Term Care (MOHLTC). The study sponsors did not participate in the design and conduct of the study; collection, management, analysis and interpretation of the data; preparation, review or approval of the manuscript; or the decision to submit the manuscript for publication.

Disclaimer: The opinions, results and conclusions reported in this paper are those of the authors and are independent from the funding sources. No endorsement by ICES, PHO, or MOHLTC is intended or should be inferred.

Acknowledgements: We would like to thank Vanessa Allen and Alex Marchand-Austin for facilitating access to PHO Laboratory's chlamydia testing data.

Author Contributions: Dr Naimer, Mr Campitelli, Dr Kwong, Mr Bhatia, and Dr Moineddin had access to all the data in the study and take responsibility for the integrity of the data and the accuracy of the data analysis. These datasets were linked using unique encoded identifiers and analyzed at the Institute for Clinical Evaluative Sciences. Additional analyses of aggregated data were conducted at the Department of Family and Community Medicine, University of Toronto.

Study concept and design: Naimer, Kwong, Mclsaac, Moineddin, Bhatia Acquisition of the data: Kwong, Campitelli, Whelan

Analysis and interpretation of the data: Naimer, Kwong, Bhatia, Moineddin, Mclsaac, Whelan

Drafting of the manuscript: Naimer, Kwong Bhatia, Moineddin

Literature search: Naimer

Critical revision of the manuscript for intellectual content: Kwong, Naimer, Bhatia, Moineddin, Whelan, Mclsaac, Campitelli, Macdonald, Lofters,

Tuite, Bogler, Permaul

Statistical analysis: Bhatia, Moineddin, Campitelli

Administrative, technical or material support: Permaul

Study supervision: Mclsaac

Supplementary materials: Available at http://www.AnnFamMed. org/content/15/4/329/suppl/DC1/.

\section{References}

1. US Department of Health and Human Services. Centers for Disease Control and Prevention. National Center for HIVIAIDS, Viral Hepatitis, STD, and TB Prevention. Division of STD Prevention. Sexually Transmitted Disease Surveillance 2014. http://www.cdc.gov/std/ stats14/surv-2014-print.pdf. Accessed Mar 23, 2016.

2. Public Health Agency of Canada, Expert Working Group for the Canadian Guidelines on Sexually Transmitted Infections. Canadian guidelines on sexually transmitted infections. Government of Canada. 14 Jan. 2015. Web. Accessed Feb 2, 2015.

3. Heymann DL, ed. Control of Communicable Diseases Manual. 19th ed. Washington, DC: American Public Health Association; 2008.
4. Centers for Disease Control and Prevention (CDC). CDC Grand Rounds: Chlamydia prevention: challenges and strategies for reducing disease burden and sequelae. MMWR Morb Mortal W/kly Rep. 2011;60(12):370-373.

5. Bowden FJ, Currie MJ, Toyne H, et al. Screening for Chlamydia trachomatis at the time of routine Pap smear in general practice: a cluster randomised controlled trial. Med J Aust. 2008;188(2):76-80.

6. U.S. Preventive Services Task Force. Screening for cervical cancer: Topic page, 2012. http://www.uspreventiveservicestaskforce.org/ uspstf/uspscerv.htm. Accessed Apr 19, 2016

7. Cancer Care Ontario. Ontario cervical screening cytology guidelines summary. Toronto, ON: Ontario Cervical Cancer Screening Program, 2012. https://cancercare.on.ca/common/pages/UserFile. aspx?fileld=13104. Acc essed Apr 19, 2016.

8. Dickinson J, Tsakonas E, Conner Gorber S, et al.; Canadian Task Force on Preventive Health Care. Recommendations on screening for cervical cancer. CMAJ. 2013;185(1):35-45.

9. Ontario Ministry of Health and Long Term Care. Sexual Health Clinics, 2015. https://www.ontario.ca/page/sexual-health-clinics. Accessed Apr 19, 2016.

10. Chan B. Supply of Physicians' Services in Ontario. Toronto, ON: Institute for Clinical Evaluative Sciences, 1999.

11. Lofters AK, Moineddin R, Hwang SW, Glazier RH. Low rates of cervical cancer screening among urban immigrants: a populationbased study in Ontario, Canada. Med Care. 2010;48(7):611-618.

12. Burchell AN, Grewal R, Allen VG, et al.; OHTN Cohort Study Team. Modest rise in chlamydia and gonorrhoea testing did not increase case detection in a clinical HIV cohort in Ontario, Canada. Sex Transm Infect. 2014;90(8):608-614.

13. Ontario Regulation 559/91: Specification of reportable diseases, Health Protection and Promotion Act, R.S.O. 1990, c. H.7. https:// www.ontario.ca/laws/regulation/910559. Accessed Apr 19, 2016.

14. Ontario Ministry of Health and Long-Term Care:IntelliHEALTH ONTARIO.

15. Bogler T, Farber A, Stall N, et al. Missed connections: Unintended consequences of updated cervical cancer screening guidelines on screening rates for sexually transmitted infections. Can Fam Physician. 2015;61(10):e459-e466.

16. Ursu A, Sen A, Ruffin M. Impact of cervical cancer screening guidelines on screening for chlamydia. Ann Fam Med. 2015;13(4):361-363.

17. Ontario Agency for Health Protection and Promotion (Public Health Ontario). Monthly infectious diseases surveillance report. Toronto, ON: Queen's Printer for Ontario; 2016. https://www.publichealthontario.ca/en/DataAndAnalytics/Documents/PHO_Monthly_ Infectious_Diseases_Surveillance_Report_-_January_2016.pdf. Accessed Apr 19, 2016.

18. Chernesky MA. The laboratory diagnosis of Chlamydia trachomatis infections. Can J Infect Dis Med Microbiol. 2005;16(1):39-44.

19. Tanksley A, Cifu AS. Screening for Gonorrhea, Chlamydia, and Hepatitis B. JAMA. 2016;315(12):1278-1279.

20. Lofters A. Cervical cancer screening among immigrants to Ontario [dissertation]. Toronto (ON): University of Toronto, 2012.

21. Qaseem A, Humphrey LL, Harris R, Starkey M, Denberg TD; Clinical Guidelines Committee of the American College of Physicians. Screening pelvic examination in adult women: a clinical practice guideline from the American College of Physicians. Ann Intern Med. 2014;161(1):67-72.

22. Public Health Agency of Canada, Centre for Communicable Diseases and Infection Control. Canadian guidelines on sexually transmitted infections: Section 5 - Management and Treatment of Specific Infections: Chlamydial Infections. http://www.phac-aspc.gc.ca/std-mts/ sti-its/cgsti-ldcits/section-5-2-eng.php. Accessed Jan 17, 2017.

23. Guy RJ, Ali H, Liu B, et al. Efficacy of interventions to increase the uptake of chlamydia screening in primary care: a systematic review. BMC Infect Dis. 2011;11(11):211.

24. Shafer MA, Moncada J, Boyer CB, Betsinger K, Flinn SD, Schachter J. Comparing first-void urine specimens, self-collected vaginal swabs, and endocervical specimens to detect Chlamydia trachomatis and Neisseria gonorrhoeae by a nucleic acid amplification test. J Clin Microbiol. 2003;41(9):4395-4399. 